\title{
ABORDARE SUSTENABILĂ
}

lect. dr. arh. Adrian Moleavin

Universitatea de Arhitectură și Urbanism „Ion Mincu”, București

adrian.moleavin@uauim.ro

\section{Introducere}

SUSTENABILITATE (< engl. sustainable) s. f. Calitate a unei activități antropice de a se desfășura fără a epuiza resursele disponibile și fără a distruge mediul, deci fără a compromite posibilitățile de satisfacere a nevoilor generațiilor următoare. (https://dexonline.ro/definitie/sustenabilitate)

Preocupările arhitecților pentru ecologie, durabilitate și sustenabilitate își au originea în anii '70, respectiv în anii crizei petrolului, ce au impus o reconsiderare a consumului de energie în utilizarea construcțiilor, cu implicații directe în arhitectură.

Din nefericire, problema reducerii consumului de energie în clădiri a fost privită mai mult ca una tehnică și mai puțin una arhitecturală, un stigmat fals, pe care arhitectura eco-sustenabilă îl poartă până în ziua de azi.

Motivele acestei stări de fapt sunt psihologice și sunt susținute de o înțelegere limitată a universului nostru existențial, respectiv cosmologia materialist-mecanicistă, care domină încă în societatea umană. Această viziune proclamă dihotomia eu-lume ca principiu fundamental și materialismul ca realitate esențială a universului. Deși această viziune științifică a fost fundamentată înaintea descoperirii nivelurilor cuantice ale realității, înainte de teoria haosului sau știința complexității, înainte de redefinirea poziției umanității ca parte integrantă a ecosistemului, cunoștințe care au schimbat fundamental paradigmele cosmologice științifice, în sfera vieții de zi cu zi suntem încă tributari mentalităților și tiparelor de viață bazate pe o viziune limitată asupra noastră și a mediului nostru de viață.

Acest mod de a gândi și de a acționa a făcut ca, timp de decenii, aplicarea principiilor sustenabilității în domeniul construcțiilor să fie evitată aproape cu orice preț, atât de către investitori, cât și de către proiectanți, deoarece: 1 . Construcțiile ar presupune o investiție mai mare, ceea ce contravine principiilor economiei capitaliste și 2. Arhitectura ar fi constrânsă să respecte un anumit set de principii care ar redefini estetica și funcționalitatea clădirilor într-un mod care s-ar opune starhitecturii. Pentru mult timp, fără a cerceta cu adevărat problema, arhitecții au considerat că arhitectura ecologică este ... urâtă şi prea limitativă.

Deși știința a depășit viziunea materialist - mecanicistă, societatea umană își bazează încă tiparele de viață (producție, muncă, locuire, construire, etc) pe acest mod limitat de a înțelege realitatea în care trăim!

Orice privire obiectivă asupra evenimentelor globale, în orice direcție ar fi îndreptată, ne arată că societatea umană traversează o perioadă de transformări profunde. Dar, așa cum cunoaștem din domeniul psihologiei, orice transformare este declanșată de un eveniment numit criză. lar istoria recentă ne spune că crizele se înmulțesc și se adâncesc. 
Prima criză economică mondială, cunoscută sub numele de The Great Depression, a început în 1929 cu căderea bursei de pe Wall Street, New York. La aproape 50 de ani mai târziu, în 1973, a avut loc criza petrolului. Apoi, numai aproximativ 25 de ani mai târziu, în anul 2000, a avut loc recesiunea economică ce a afectat în special țările dezvoltate și, în 2008, la doar 8 ani distanță, s-a declanșat criza financiară ce a reverberat până în 2014. în 2020, la o depărtare în timp de numai 6 ani, avem de-a face cu o nouă criză financiară, de această dată cuplată cu una medicală, de sănătate.

În mod evident avem de-a face cu o contracție a perioadelor de stabilitate și înmulțire a momentelor de criză economică. Mai mult decât atât, avem de-a face cu o criză demografică, politică, culturală și, poate cele mai importante dintre toate, criza ecologică, cu accentul pe poluare, și cea climatică.

Faptul că aceste crize se repetă și se acutizează ne arată că modul nostru de viață necesită o transformare, o schimbare care încă nu a avut loc!

Dar, însăși faptul că aceste crize au loc și, mai ales, din faptul că nu reușim să redresăm balanța în favoarea noastră, înțelegem că nu putem privi societatea umană ca fiind separată de mediul său de viață. În contextul în care domeniul construcțiilor, privit de la producerea materialelor de construcție şi până în momentul demolării, reprezintă cel mai mare consumator de energie, la care trebuie să adăugăm şi poluarea produsă în acest proces, domeniul arhitecturii devine crucial.

Problema unui mod de viață nesustenabil merge însă până la rădăcinile cele mai vechi ale rasei umane. Conform cunoscutului istoric Yuval Noah Harrari, în cartea Sapiens - O scurta istorie a omenirii, societatea umana a fost nesustenabilă încă de la apariția primilor Homo Sapiens. Migrația populațiilor de Homo Sapiens a fost întotdeauna urmată de dispariția animalelor mari.

Însă, dacă până la sfârșitul secolului 20, tiparele de viață nesustenabile nu au amenințat însăși existența umană pe această planetă, amenințările Antropocenului ne sunt acum binecunoscute tuturor, fie şi doar dacă amintim faptul că Jakarta, capitala Indoneziei, se află deja în proces de relocare datorită încălzirii climatice, respectiv a creşterii nivelului oceanului.

Necesitatea de construcții noi creşte mai rapid decât capacitatea noastră de construcție (datorită creşterii populației). Mediul construit artificial este cel mai mare poluant al planetei.

Ecuația este evidentă şi pentru ca rezultatul să fie unul pozitiv, necunoscuta trebuie să răspundă întrebării: cum construiesc, utilizez şi reciclez construcțiile fără poluare?

În concluzie, arhitectura ecologică, sustenabilă și durabilă, nu reprezintă doar răspunsul la problemele actuale privind poluarea sau schimbările climatice, ci și expresia spațialconstructivă și estetică a unei noi cosmologii științifice care privește omul și societatea umană ca parte integrantă a unui ecosistem planetar.

Mai mult decât o necesitate a supraviețuirii, sustenabilitatea mediului construit edifică unele dintre cele mai înalte aspirații umane: armonia (Edwards: 2005).

\section{Raportarea la obiective didactice}

Din ce în ce mai mult, dimensiunea sustenabilă a mediului construit este integrată în obiectivele temelor cadru de proiectare. Dacă în temele anilor 1-3 sustenabilitatea și durabilitatea apar doar ca teme de reflecție, fără a deveni în mod real factori generatori, în anii 4-5 apar o serie de obiective clar definite. 
În temele de an 4, semestrul 1 (7) apare ca obiectiv Înțelegerea, însușirea, aplicarea și dezvoltarea principiilor tehnologice adaptate programului și în legătură cu impactul asupra mediului. Pentru a putea răspunde acestor deziderate este nevoie de înțelegerea impactului construcțiilor asupra mediului, respectiv a relației dintre consumul de energie și poluare, influența tehnologiei asupra reducerii consumului de energie și colectarea și utilizarea energiilor regenerabile. Dezvoltarea tehnologică accentuată a secolului 20, și chiar mai rapid a secolului 21, a creat impresia că tehnologia este astăzi capabilă de a rezolva orice problemă. Însă, trebuie avut în vedere că, dacă tehnologia ne oferă, de exemplu, capacitatea de a colecta și utiliza energiile regenerabile, randamentul acestor tehnologii este încă foarte scăzut și poluarea produsă în urma procesului de producție a sistemelor tehnologice depășește negativ beneficiul adus de utilizarea acestora. Tehnologia trebuie văzută ca un factor ajutător, compensator, dar nu ca un panaceu universal.

Un alt obiectiv, ce apare în temele de an 4, semestrul 2 (8) urmărește Dezvoltarea proiectului pornind de la înțelegerea unor elemente de sustenabilitate ce pot fi integrate în proiect. Acest deziderat ar fi trebuit, cu siguranță, să apară înaintea studiului adjuvanților tehnologici întrucât implică înțelegerea conexiunilor dintre mediu construit - om - mediu natural - poluare. Mai mult decât orice, este necesară înțelegerea arhitecturii/construcției ca parte a unui context extins, pe de o parte spațial, ca parte a unui eco-sistem natural-artificial și, pe de altă parte, temporal, pe toată durata de viață, de la concepere și până la reciclare. Interesant de studiat și căutat sunt beneficiile, plus-valoarea pe care arhitectura/construcția, prin însăși prezența sau/și utilizarea ei le poate aduce ecosistemului natural-artificial, îmbunătățind prin aceasta calitatea vieții umane a utilizatorilor direcți sau indirecți.

În anul 5, semestrele 1 și 2 (9 și 10) se urmărește Înțelegerea și aplicarea unor principii arhitecturale și conexe ce țin de o reducere sau control al consumului de energie al clădirilor și incorporarea unor elemente de sustenabilitate în toate scările de intervenție. Orice proiect de arhitectură dezvoltă o relație de interdependență cu mediul său înconjurător. Această relație se traduce într-o serie de principii care determină 'comportamentul' clădirii. Enunțate încă din faza de concept a proiectului, acestea influențează arhitectura clădirii, indiferent de scara la care o lecturăm. Fie că este vorba de compoziția volumetrică, de materialitate sau de un simplu detaliu tehnic, principiile sustenabile încorporate trebuie să își păstreze valabilitatea și funcționalitatea.

\section{Cercetare - criterii, concepte}

"If we are seeking a new world, to find it we must sail past the edge of the map, past our existing beliefs and worldview."

(Beth Carruthers, membru al juriului competiției Land Art Generator în Koh şi Wong (Eds.), 2012: 27).

Abordarea pasivă - Arhitectura care răspunde într-un mod pasiv condițiilor locale de climă, fără aportul sistemelor mecanice (active) de instalații.

Arhitectura bioclimatică (Lebedev şi Jurov, 1985; Olgyay, 2015) tratează atât adaptarea arhitecturii clădirilor la condițiile de climat (microclimat) şi relief (protecția împotriva frigului, protecția împotriva căldurii, protecția împotriva intemperiilor, adaptarea la topografia terenului, orientarea clădirii, alegerea (natura) materialelor de construcție, conformarea şi poziționarea deschiderilor, etc, cât şi contextul cultural şi istoric, fiind influențată de ocupația 
locuitorilor, tradițiile (tiparele) de locuire, necesitățile utilizatorilor, tradițiile artistice locale sau influențele istorice.

Pentru a controla microclimatul interior al clădirilor, arhitectura bioclimatică utilizează procesele naturale fizice fără nici un alt consum de energie. Arhitectura / construcția interacționează activ şi continuu cu mediul înconjurător, devine parte integrantă a acestuia, asigurând astfel nu numai rolul de protecție a utilizatorilor, dar şi de interfață / membrană permeabilă, cu caracter osmotic, între mediul natural şi om.

Abordarea activă - Orice alt tip de arhitectură / construcție care utilizează sisteme mecanice de instalații pentru adaptarea și menținerea climatului interior.

Casa Pasivă (Passive House f.a.) este un standard al construcțiilor conceput pentru a asigura simultan condițiile eficienței energetice, confortului și eficienței economice. Deși utilizează sisteme de instalații, se numește Casa Pasivă deoarece accentul este pus pe proiectarea bioclimatică pasivă. Condițiile certificării unei construcții la standardul Casa Pasivă sunt aceleași indiferent de locația geografică (climă, relief, etc) a viitoarei clădiri.

Arhitectura ecologică (Roaf, Fuentes şi Thomas, 2007) Suplimentar față de sistemul Casa Pasivă, arhitectura ecologică acordă o atenție mult mai mare amprentei ecologice a viitoarelor clădiri.

Amprenta ecologică este o metodă de a măsura sustenabilitatea. Ea măsoară, in hectare de teren agricol productiv, câtă suprafață este necesară pentru a susține un anumit stil de viață. Amprenta ecologică se calculează pentru întreaga societate umană, pentru diferite populații, țări, regiuni, orașe, clădiri sau chiar pentru o singură persoană (Bastianoni, Galli, Niccolucci şi Pulselli, 2006, Lim, 2018, Ecological Footprint f.a.).

Arhitectura ecologică pune accentul pe ideea că mediul construit este parte a ecosistemului planetar. Altfel spus, construcțiile trebuie să intre într-o relație sistemică cu mediul natural întrun mod natural, ecologic, durabil.

Conceptul Cradle to Cradle. (C2C sau Arhitectura regenerativă) (Braungart şi McDonough, 2009) reprezintă un mod nou de a privi relația societății umane cu mediul său de viață ce vizează transformarea proceselor liniare într-unele circulare. În procesele liniare mediul natural este sacrificat în vederea colectării de materiale brute, se consumă cantități uriașe de energie pentru producerea de obiecte, inclusiv construcții, care sunt aruncate sau arse la finalul utilizării lor, în tot acest proces producându-se cantități uriașe de gunoi și toxine (poluare). În procesele circulare resursele şi materialele sunt asimilate unor nutrienți care circulă între sisteme diferite ale ecosistemului natural într-un mod sănătos, ecologic, fără a produce deșeuri și poluare. În acest sistem orice produs trebuie să poată fi reciclat continuu sau, altfel spus, ceea ce este deșeu pentru societatea umană trebuie să devină nutrient pentru natură, acesta fiind singurul mod în care se poate asigura o creștere continuă, sustenabilă, a consumului.

Arhitectura vie (Living Architecture). Este definită ca arhitectura care utilizează resursele, forțele şi posibilitațile mediului natural şi ale organismelor sale pentru a construi eficient şi sustenabil. Deşi conceptul este de multe ori asociat cu procesul de a utiliza structuri vegetale pentru a realiza structuri utile omului, există abordări corolare care interpretează sistemele naturale într-o cheie nouă, ştiințifică, creativă, pentru a ajunge la acelaşi rezultat.

Arhitectura bionică (Cogdell, 2018, LIAR f.a.) este definită ca o mişcare contemporană în domeniul arhitecturii care studiază adaptarea sistemelor sau a organismelor biologice, din punct de vedere fiziologic, comportamental sau structural, ca sursă de inspirație pentru 
proiectarea şi construcția clădirilor. Dacă adăugăm acestei linii de gândire dezideratul ecologic, această direcție se apropie foarte mult de o ideea unui mediu construit sustenabil. Notăm doar 3 reprezentanți: Buckminster Fuller (Fuller, f.a.), Maria Rosa Cervera (Cervera şi Pioz, 2015) şi Neri Oxman(Oxman, f.a.).

\section{Impact}

Arhitectul și profesorul american John Lobell (Lobell, f.a.) afirmă că arhitectura trebuie să fie în și din timpul său și pentru aceasta ea trebuie să îndeplinească 4 deziderate:

- este construită în spațiul și timpul erei sale,

- este construită din materialele și metodele de construcție ale erei sale,

- este construită din structurile conștiinței oamenilor erei sale,

- este construită în contextul socio-cultural al erei sale. (Lobell, f.a.)

Orice proiect de arhitectură trebuie să răspundă acestor deziderate. O abordare sustenabilă poate să genereze o arhitectură cu implicații multiple:

- îmbunătățirea calității mediului, prin economia de energie, reducerea poluării, utilizarea resurselor de energie regenerabile, utilizarea materialelor naturale, utilizarea tehnicilor de construcție nepoluante; calitatea ambientului interior, prin asigurarea parametrilor optimi ai micro-climatului interior [Am folosit materialele și metodele de construcție ale prezentului? Care sunt materialele şî tehnologiile viitorului?];

_ redefinirea raporturilor om - mediu construit - mediu natural, printr-o înțelegere sistemică, în care cei trei factori nu constituie entități separate, ci părți ale unui ecosistem natural-artificial integrat [Prin propunerea mea răspund structurilor conștiinței oamenilor prezentului?]

_ redefinirea tiparelor de locuire / utilizare a construcțiilor, redefinirea schemelor funcționale, apariția unor noi funcțiuni [Arhitectura propusa se încadrează în contextul socio-cultural al prezentului? Dar cum va arata acest context în viitor?]

\section{Exemple}

Exemplele propuse nu sunt specifice, ci categorii care să ofere indicii despre posibilitățile prezentului, să incite la o cercetare personală care să depășească dimensiunea tehnică a construcțiilor sustenabile și să provoace generarea de inovație conceptuală dincolo de un design reușit.

\section{Grupul Hyperbody, Delft University of Technology (Hyperbody, f.a.)}

Grupul Hyperbody, înființat în cadru universității TU Delft, din Olanda, este dedicat utilizării tehnicii și metodelor de design avansate pentru generarea unei arhitecturi interactive nonstandard.

\section{Grupul pentru arhitectura avansată (AAG), Barcelona (Advanced Architecture Group, f.a.)}

Grupul pentru arhitectura avansată (AAG) este un grup de cercetare interdisciplinară ce utilizează tehnologii emergente informaționale, interactive și de producție, pentru a proiecta și transforma orașe, clădiri și spații publice. 
Proiectul Venus, Florida (Araya, 2020)

Proiectul Venus reprezintă o altă viziune asupra viitorului, o viziune ce arată implicațiile transfigurative profunde pe care le are adoptarea unei conștiințe ecologice, o gândire și acțiune etică și morală, asupra tiparelor de viață umane.

\section{Recomandări bibliografice}

Feireiss, K., Feireiss, L., (Eds.). (2008). Architecture of Change - Sustainability and Humanity in the Buit Environment. Gestalten.

"Today's architects and engineers are increasingly being asked to address issues of sustainability in our changing world. This book presents outstanding architectural projects and initiatives that combine creativity, scientific knowledge, technical innovation, social engagement and a strong sense of responsibility to address environmental challenges."

Gadanho, P. (Ed.). (2018). Eco-Visionaries. Art, Architecture and New Media After the Anthropocene. Hatje Cantz Verlag.

„Eco-Visionaries presents contemporary positions in art and architecture that seek out new ways to frame current environmental issues. Transcending mainstream notions of sustainability, this comprehensive volume shows the ways in which artists investigate alternative visions regarding humankind's place on earth ...".

Koh, R., Wong, S. (Eds.). (2012). The Time is Now. Public Art of the Sustainable City. Land Art Generator Initiative. UAE. Page One Publishing

"The Land Art Generator Initiative provides us with a unique preview of future generations' industrial surroundings. It throws down the challenge to design and construct public art installations that have the added benefit of large scale clean energy generation. Each sculpture continuously distributes clean energy into the electrical grid, with the potential to power thousands of homes."

\section{Referinţe}

Advanced Architecture Group. (f.a.). IAAC. Preluat în 30 septembrie 2020, din https://iaac.net/researchdepartments/advanced-architecture-group/

Araya, D. (2020, septembrie 1). Is The Venus Project The Next Stage In Human Evolution? Forbes. https://www.forbes.com/sites/danielaraya/2020/09/01/is-the-venus-project-the-next-stage-inhuman-evolution/\#46acbfbd5c35

Bastianoni S., Galli A., Niccolucci V., Pulselli R. M. (2006). The ecological footprint of building construction. WIT Transactions on Ecology and the Environment, vol. 93, https://www.doi.org/10.2495/SC060331

Braungart, M., McDonough, W. (2009 [2002]). Cradle to Cradle: Remaking the way we make things. Londra: Vintage Books.

Cervera, R. M., Pioz, J. (2015). Bionic Architecture: Learning From Nature. Hamburg: Gingko Press.

Cogdell, C. (2018). Towards a Living Archtiecture? Minneapolis: University of Minmesota Press. Preluat în 30 septembrie 2020 din https://manifold.umn.edu/read/untitled-f1773d15-0794-4df3-a4cb44234533f676/section/717beb44-986d-405f-9823-c4dae0547d0f\#cvi

Ecological Footprint (f.a.). Preluat în 30 septembrie 2020, din http://www.footprintcalculator.org/ 
Edwards, A. R. (2005). The Sustainability Revolution: Portrait of a Paradigm Shift. Gabriola: New Society Publishers

Feireiss, K., Feireiss, L., (Eds.). (2008). Architecture of Change - Sustainability and Humanity in the Buit Environment. Gestalten.

Fuller, B. (f.a.). Preluat în 30 septembrie 2020, din https://www.bfi.org/.

Gadanho, P. (Ed.). (2018). Eco-Visionaries. Art, Architecture and New Media After the Anthropocene. Hatje Cantz Verlag.

Harrari, Y. N. (2017). în Sapiens. Scurtă istorie a omenirii. Iaşi: Polirom.

Hyperbody. (f.a.). Hyperbody Archive. Preluat în 30 septembrie 2020, din www.hyperbody.nl

Koh, R., Wong, S. (Eds.). (2012). The Time is Now. Public Art of the Sustainable City. Land Art Generator Initiative. UAE. Page One Publishing

Lebedev, I. S., Jurov, C. (1985). Arhitectura bionica si bioclimatică. Bucureşti: Ed. Tehnică.

LIAR (f.a.). Living Architecture. Preluat în 30 septembrie 2020, din https://livingarchitecture-h2020.eu/.

Lim, A. (2018) What is Ecological Footprint? Definition and How to Calculate It. ThoughtCo, Aug. 28, 2020, thoughtco.com/what-is-ecological-footprint-4580244

Lobell, J. (f.a.). Quantum Theoretical Issues in Architecture: It's A Lot Stranger than We Think. John Lobell. Preluat în 30 septembrie 2020, din https://johnlobell.com/quantum-theoretical-issues-inarchitecture-its-a-lot-stranger-than-we-think/

Olgyay, V. (2015 [1963]). Design With Climate. Bioclimatic Approach to Architectural Regionalism. New Jersey: Princeton University Press.

Oxman, N. (f.a.). Preluat în 30 septembrie 2020, din https://oxman.com/.

Passive House (f.a.). Preluat în 30 septembrie 2020, din https://passivehouse.com/index.html/.

Roaf, S., Fuentes, M., Thomas, S. (2007 [2001]). Ecohouse: A Design Guide. Oxford: Elsevier Architectural Press.

Vallas, T., \& Courard, L. (2017). Using nature in architecture: Building a living house with mycelium and trees. Frontiers of Architectural Research, 6(3), 318-328. https://doi.org/10.1016/j.foar.2017.05.003. 